\title{
Acceptance of mobile payments by retailers using UTAUT model
}

\author{
Nor Hapiza Mohd Ariffin, Fauziah Ahmad, Umar Mohd Haneef \\ Faculty of Computer and Mathematical Sciences, University Teknologi MARA, Malaysia
}

\begin{tabular}{l}
\hline \hline Article Info \\
\hline Article history: \\
Received Dec 14, 2019 \\
Revised Feb 3, 2020 \\
Accepted Feb 20, 2020 \\
\hline
\end{tabular}

\section{Keywords:}

Mobile payment

UTAUT Model

Retailers

\begin{abstract}
Mobile payment is a form of payment transaction processing where the payer utilizes mobile communication methods together with mobile devices to initiate, authorize or complete payment. Hence, with the huge increase in mobile device usage, the retail sector will be able to collect large volumes of data. Unfortunately, most Malaysians still do not make full use of digital payments or cashless payments. Consumers in South East Asia still tend to use money or bank cards, and companies have been "limitedly effective" in encouraging a cashless revolution. The objective of this study was to identify the acceptance of mobile payment by retailers, the factors that contribute to the acceptance of mobile payment and the relationship between the factors were also the aim of this research. Several factors were contributing to mobile payments such as performance expectancy, effort expectancy, social influence, facilitating conditions, habit, privacy, perceived security and intentions which was based on the UTAUT model. This study used questionnaires to collect data and the data analysis was carried out using SPSS software. Based on the analysis that has been conducted, it can be seen that all the hypotheses of this research have a significant relationship except for the relationship between privacy and intentions that has a negative linear relationship. It is hoped that this research will give values to retailers with an understanding of the contributing factors that affect their acceptance of mobile payment technology in the retailing business.
\end{abstract}

Copyright $(0) 2020$ Institute of Advanced Engineering and Science. All rights reserved.

\section{Corresponding Author:}

Nor Hapiza Mohd Ariffin,

Department of Information Systems,

Faculty of Computer and Mathematical Sciences,

Universiti Teknologi Mara, 40450, Shah Alam, Selangor, Malaysia.

Email: hapiza@tmsk.uitm.edu.my

\section{INTRODUCTION}

Mobile payment is "a type of payment transaction processing in which the payer uses mobile communication techniques in conjunction with mobile devices for the initiation, authorization, or completion of payment" [1]. Mobile payments are carried out by banks and financial companies, mobile network operators, software developers, device manufacturers, service providers, traders, customers, traders and regulatory bodies [2-4]. All of these can be grouped into various groups, including consumers, mobile payment providers, technology manufacturers and retailers [5]. Mobile payments are paid using a mobile phone as a payment tool. Mobile payments are probably the future of electronic payment development [6]. Mobile payments in the retail industry can be a huge data source. With the enormous increase in the usage of mobile devices, the retail sector will be able to collect data from a wide range of sources and speeds in large volumes [7-9].

According to [10], a retailer is a company that sells directly to the consumer. A retailer buys products from a manufacturer, distributor or wholesaler and sells them at a marked price to the customer. For example, when a retailer is registered, it can certainly be official retailers that sell a certain brand of mobile phones. As a registered distributor and retailer, the company will not only sell mobile phones but also be able to fulfill 
the sale with a manufacturer's guarantee. People often think of big retailers like Giant, Tesco, and Aeon when the term retailer is mentioned, however, retailers may also be small retailers, such as a corner grocery store or a family pharmacy. There are about 400 hypermarkets and supermarkets in Malaysia. The top players are Giant, AEON (Japan), The Store Corporation (Malaysia) and Tesco (UK) (source: from Beijing to Budapest, Winning Brands, Winning Formats 2005/2006). The growth of retailers in Malaysia added to the high competition between retailers, which led to the development of customer loyalty programmes. Besides, Malaysians were cautious about the financial crisis of 1997 to 1998 that caused them to be cautious about the value of products and purchases. In this context, retailers were urged to offer their customers loyalty programs to convey the value of the purchase and, in the meantime, they are used as a tool to foster relationships with their customers. There are many types of retailers that a business can be in. There are department stores, discount stores, supermarkets, warehouse stores, grocery stores, convenient stores, specialty stores, malls, e-Tailers and Ringgit stores.

There is forecasting that by 2050 Malaysia appears to be becoming a cashless society. It can be seen that digital payment platforms emerging in Malaysia, although it is 31 years from that year. Currently, our neighbouring countries, Singapore, the Netherlands and France, are the best cashless countries. It is also said to be all the rage in countries like China and India [11].

Mobile devices have changed our way of communicating and staying connected and the world of retail and banking is changing. According to the Nielsen Global Survey of Mobile Shopping, Banking \& Payment (2016), about $72 \%$ of Malaysians are equally concerned with mobile payment security. Malaysia was relatively slow in the high-tech payout game, similar to the rest of southeast Asia. Consumers still preferred to use cash or bank cards in South East Asia, and banks had been "limitedly successful" in promoting a cashless revolution, according to a recent article in the Financial Times. This could be the reason for the low digital payment rate in Malaysia. Furthermore, digital payments or cashless payments were not fully being utilized by the majority of Malaysians [11]. To be worst, many retailers in Malaysia still preferred to use cash instead of digital cash. "For mobile payments to be successful, one needs a combination of factors, including interest and eagerness from customers to use mobile as a device to pay, a wide merchant network availability where customers can pay and network effect that can ensure a seamless user experience," said Tengku Datuk Seri Zafrul Aziz, the chief executive officer of the CIMB Group Holdings Bhd group [12]. So it is important to study why the acceptance of mobile payments is still low in Malaysia. Therefore it is essential to understand first what are the factors that support the acceptance of the mobile payment system.

Several factors contribute to the utilization of mobile payments. Acceptance remains a key factor in the development of new technologies. The development and deployment of new financial technology had been primarily slowed down by legacy issues, practices, systems and the culture of companies. As said by Tengku Seri Zafrul Aziz, the penetration of digital wallets accounts for only 11 percent in Malaysia, as Fintech Singapore reported. There was also a connection between these factors that affect the use of mobile payments. Mobile payments were expected to play an important role in accelerating the reduction in cash use. Given the high rate of mobile phone penetration in Malaysia, mobile phones can easily be used to make and accept payments for point of sale (POS) terminals without additional infrastructure costs. At the same time, consumers in Malaysia also became more familiar with making transactions using the mobile channel. In 2017, the number of mobile bank accounts rose to 11.5 million (2011: 1.6 million). Financial transactions using mobile banking have also increased at an annual growth rate of $91 \%$ over the past seven years, totaling 106.1 million transactions valued at RM48.3 billion in 2017 (2011: 2.2 million transactions; RM0.9 billion).

\section{RESEARCH METHOD}

Various models and structures have been produced to clarify client acceptance of new technologies and these models present factors that can influence the client acceptance, for example, Technology Acceptance Model (TAM), Theory of Planned Behaviour (TPB) and Diffusion of Innovation theory (DOI), Theory of Reasoned Action (TRA), Model of PC Utilization (MPCU), Motivational Model (MM), Unified Theory of Acceptance and Use of Technology (UTAUT), Social Cognitive Theory (SCT) and numerous researches have utilized these common models to do their research. Previous research shows that the acceptance model (TAM) and the Unified Theory of Technology Acceptance and Use (UTAUT) were the most widely used model to understand the factors affecting mobile payments and other technologies. The UTAUT model [13] incorporates eight theories of user acceptance into existing IS literature. TAM, DOI, MM, TRA, TPB, MPCU, SCT and a model combining TAM and TPB. Figure 1 illustrates the model used in the research which is based on research by [14].

Meaning of each variables

a. Performance expectancy; Performance expectancy refers to an individual's perception that a IS facilitates the completion of a task [13]. 
b. Effort expectancy; Defined as an individual's evaluation ofthe effort necessary to complete a task using a given IS $[13,15]$.

c. Facilitating, Conditions represent the extent to which a consumer believes that resources exist and they facilitate the task completion using as IS [16].

d. Social influences, Defined as the extent to which an individual perceives the degree of approval of a certain behavior by important referents $[13,15]$.

e. Hedonic motivation: Hedonic motivation represents the extent to which consumers believe that using an IS system is entertaining [15].

f. Habit. In [17 and 15], defined the habit as the degree to which consumers tend to perform the usage of technologies or the usage of technology products behaviors automatically because of learning.

g. General privacy; Privacy reflects the individuals' rights to be left alone, and has critical connotations in the contemporary society [18].

h. Perceived security; In commercial contexts, perceived security reflects consumers' perceptions that a certain system is secure to conduct transactions [19].

i. Intentions; To perform a behavior result from conscious decision-making [20]. As the conative component of attitude and it has usually been assumed that this conative component is related to the attitude's affective component [21].

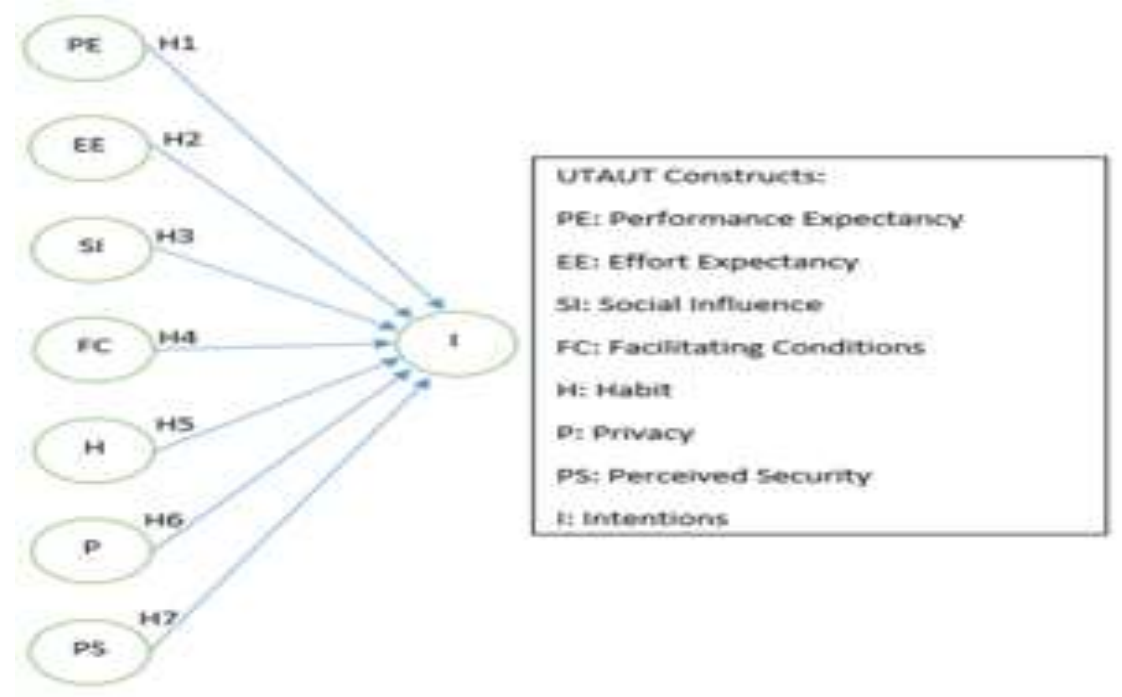

Figure 1. UTAUT (Research Model Adapted From [14])

Survey is a process of collecting information from a group of people, usually intending to represent the results to a larger population. Surveys serve as a crucial source of data for nearly everyone involved in the information economy. The reason why this research uses a survey instead of conducting an interview was that the interview approach will be limited to a small number of participants. Therefore, this research used quantitative research through a survey questionnaire. This research was done on retailers that are located in Section 7, Shah Alam, Selangor. Section 7 was selected due to the convenience of the area to the researcher, and the large number of shops located there. The retailers were chosen using a convenience sampling technique. The retailers can come from a variety of retail companies, such as convenience stores and other companies that run businesses through retail.

Unified Theory of Acceptance and Use of Technology (UTAUT) model had been adapted because this model is designed using the 14 initial buildings from eight acceptance models. According to [22], UTAUT aims to explain user intentions to use information technology or information system and subsequent usage behaviour. UTAUT suggests four core constructs to explain and predict user acceptance of technology adoption, which was: performance expectancy (equivalent to perceived usefulness), effort expectancy (equivalent to perceived ease of use), facilitating conditions and social influence. These constructs explain up to $70 \%$ of the variance in usage intention. This model was chosen because it is in line with the objectives of this research. 
The main purpose of this research is to study the utilization of mobile payments among retailers. It consists of three objectives, which are first, to identify the acceptance of mobile payment by retailers, secondly, to determine the factors that contribute to the acceptance of mobile payment and lastly, to identify the relationship between the factors affecting the acceptance of mobile payment.

The data had been collected using a survey questionnaire that adapted from [14]. The questionnaire was checked its validity by statisticians to identify possible errors such as accuracy and clarity. Then, several changes were made to improve the questionnaire, based on comments and feedback by the statisticians before it was being distributed for a pilot study. The pilot study was done on 10 respondents and it showed that Cronbach's Alpha value is 0.854 . According to [24] and [25] below 0.5 are generally unacceptable. This means that the Alpha coefficient of this pilot study was acceptable and the questionnaire was reliable. After the pilot study, the questionnaires were distributed to the actual respondents. Furthermore, based on the research model shown in Figure 1, the following hypothesized relationships were generated and tested.

H1: There is a relationship between Performance Expectancy and Intentions.

$\mathrm{H} 2$ : There is a relationship between Effort Expectancy and Intentions.

H3: There is a relationship between Social Influence and Intentions.

H4: There is a relationship between Facilitating Conditions and Intentions.

H5: There is a relationship between Habit and Intentions.

H6: There is a relationship between Privacy and Intentions.

H7: There is a relationship between Perceived Security and Intentions.

For analysis, the data had been analyzed using SPSS software to run a test of linearity, multicollinearity, Pearson correlation, and multiple linear regression.

\section{RESULTS AND ANALYSIS}

Data was collected using a questionnaire designed in two parts which respondents need to answer 41 questions form the questionnaire where the question was divided into 2 sections which are Section A and Section B. Section A is about demographic information of the respondents and Section B is about level of acceptance of mobile payments by retailers in Section 7 Shah Alam. The questionnaires were designed based on a five-point Likert scale. The five-point Likert scale ranges from (1) to (5) representing strongly agree and strongly disagree respectively, (2) and (4) represent moderately agree and disagree while (3) represent neutral. A total of 100 questionnaires were administered and 53 were returned, a response rate of 53 percent. SPSS software was the statistical tools used to capture and analyze the data from the questionnaire.

\subsection{Overview of section $A$}

About $53 \%$ of respondents were female and $47 \%$ male, with $47.2 \%$ were aged 24 and below. The second highest majority age of the respondents was 35 to 54 years old with a percentage of $35.8 \%$. Followed by respondents aged 24 to 35 and above 54 with a percentage of $15.1 \%$ and $1.9 \%$ respectively. The biggest majority type of business of the respondents' was grocery stores with a percentage of $54.7 \%$. Followed by department stores at $11.3 \%$ and Ringgit stores at $7.5 \%$. Table 1 shows the demographics of the respondents in details.

\subsection{Overview of section $B$}

There are several findings for Section B which seeks to see the level of acceptance of mobile payments by retailers. Below is the list of the findings for Section B.

a. The most common mobile payment application used by the respondents were E-Wallet with a frequency of $60.4 \%$, followed by PayPal at $41.5 \%$, and Samsung Pay at $20.8 \%$.

b. About $30.2 \%$ of respondents used mobile payment occasionally (less than once a month), $26.4 \%$ of respondents used it monthly (several times), $17 \%$ of respondents used it weekly (several times), and 9.4\% of respondents used it monthly (once).

c. For the question about "I use the mobile payment for business transactions with customers", about $41.5 \%$ of respondents agreed that they use the mobile payment for business transactions with the customer. Whereas $39.6 \%$ of respondents disagreed and $15 \%$ of respondents had a neutral opinion about it.

d. For the question about "Mobile payment ease my business", about half of the respondents which is $47.2 \%$ agreed that mobile payment eases their business. Whereas $39.6 \%$ of respondents strongly disagreed that mobile payment can ease their business and $13 \%$ of respondents had a neutral opinion about it.

e. For the question about "Mobile payment does not cause me problems", 28.3\% of respondents were unsure whether the mobile payment could cause them problems, while another $32.1 \%$ thought that it may cause 
them problems. Besides that, $39.6 \%$ of respondents strongly disagreed that mobile payment might give them problems.

f. For the question about "I use mobile payment regularly", about $37.7 \%$ of respondents agreed that they used mobile payment regularly, whereas another $45.3 \%$ of respondents disagreed that they use mobile payment regularly and about $17 \%$ undecided about how frequent their usage of mobile payment.

Table 2 illustrates about descriptive statistics for the UTAUT constructs. There were 8 values of the mean for each of the 8 constructs derived from 53 respondents as seen in Table 2. Based on table 2, it can be seen that privacy has the highest mean value of 4.34 whereas facilitating conditions has the lowest mean value of 2.88. Therefore, it shows that privacy is the factors that retailer most concern when they use mobile payments and facilitating conditions is the least contributing factor to the use of mobile payments.

Table 1. Respondent Demographics

\begin{tabular}{lll}
\hline Character & & Percent (\%) \\
\hline Gender & Male & 57.8 \\
& Female & 47.2 \\
Age & Below 24 & 47.2 \\
& 24-35 years & 15.1 \\
& 35-54 years & 35.8 \\
Type of & Above 54 years & 1.9 \\
Retailers & Grocery Stores & 54.7 \\
& Department Stores & 11.3 \\
& Ringgit Stores & 7.5 \\
& Supermarket & 5.7 \\
& Convenient stores & 5.7 \\
& Specialty stores & 5.7 \\
& E-tailers & 1.9 \\
\hline
\end{tabular}

Table 2. Mean rankings

\begin{tabular}{lc}
\hline \multicolumn{1}{c}{ Factors } & $\begin{array}{c}\text { Ranking } \\
\text { (Mean) }\end{array}$ \\
\hline Privacy & 4.3443 \\
Perceived security & 3.1981 \\
Intentions & 3.1698 \\
Social influence & 3.0991 \\
Performance & 3.0849 \\
expectancy & \\
Effort expectancy & 3.0755 \\
Habit & 3.0236 \\
Facilitating conditions & 2.8868 \\
\hline
\end{tabular}

Pearson's correlation coefficient is the test statistics that measure the statistical relationship, or association, between two continuous variables. It is a measure of the strength of the association between the two variables. Therefore, in this research, it was used for hypotheses testing. Hence, findings show that all of the dependent variables which are performance expectancy, effort expectancy, social influence, facilitating conditions, habit, privacy, and perceived security had relationships with intentions. But the only difference was that privacy had a negative relationship with intentions which is an independent variable. A negative correlation is a relationship between two variables in which one variable increases as the other decreases, and vice versa. Figure 2 below illustrates the relationship between hypotheses and its value.

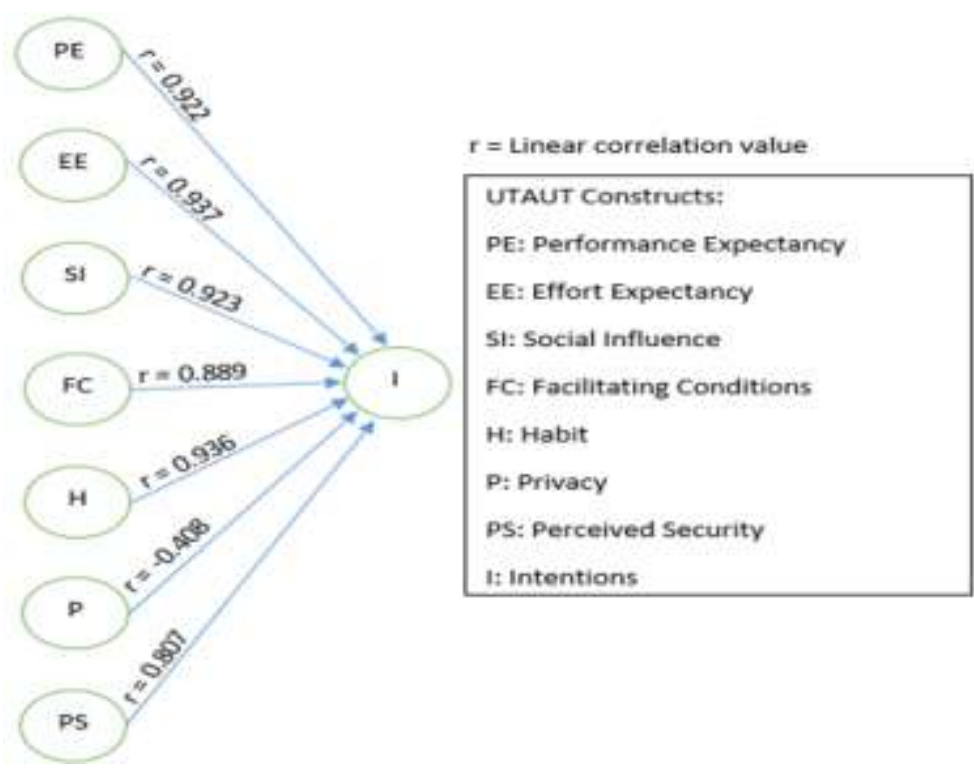

Figure 2. Hypotheses R-Values 
As a summarization, from the data analysis it can be seen that all the hypotheses acceptable as below. H1: There is a relationship between Performance Expectancy and Intentions.

H2: There is a relationship between Effort Expectancy and Intentions.

H3: There is a relationship between Social Influence and Intentions.

H4: There is a relationship between Facilitating Conditions and Intentions.

H5: There is a relationship between Habit and Intentions.

H6: There is a relationship between Privacy and Intentions.

H7: There is a relationship between Perceived Security and Intentions

\section{CONCLUSION}

Based on the findings from Section A, it can be seen that mobile payment was not fully accepted by Section 7 Shah Alam retailers.Data analysis in Section B showed that all the 7 independent variables were linear with intentions and accepted as factors that contribute towards the acceptance of the mobile payment. By this, it can be determined that performance expectancy, effort expectancy, social influence, facilitating conditions, habit, privacy and perceived security affected intentions of the respondents to use the mobile payment. Not only that, based on data analysis in Section B which using Pearson correlation analysis, it can be seen that performance expectancy, effort expectancy, social influence, facilitating conditions, habit, and perceived security had a very high effect on intentions.

Based on the results of this research, all of the hypotheses of this research have been proven except one, which is privacy and intentions has a negative linear relationship between one another. A negative linear relationship exists when one variable increases while the other variable decreases. This means that due to the increased in the privacy concerns of the respondents, it caused their low level of acceptance of mobile payments. This is what is meant by a negative linear relationship between privacy and intentions. The problem of privacy is what caused them to feel skeptical to use mobile payments.

As a conclusion, it can be seen that privacy had a negative linear correlation with intentions. This means that respondents were concerned with privacy so the intention to use mobile payment decreases. Based on this information, future researchers can further research to assess the trust of people on using mobile payment in the context of their privacy. Future researchers should come up with a study that can improve people's knowledge of privacy to further develop their trust and confidence to use mobile payment.

\section{ACKNOWLEDGEMENTS}

The researchers would like to extend the gratitude to the Faculty of Computer and Mathematical Sciences, UiTM for the financial supports and various involved reviewers in providing helpful and constructive comments, which helped improve this manuscript.

\section{REFERENCES}

[1] L. Goeke and K. Pousttchi, "A Scenario-Based Analysis of Mobile Payment Acceptance," 2010 Ninth International Conference on Mobile Business and 2010 Ninth Global Mobility Roundtable (ICMB-GMR), Athens, pp. 371-378, 2010.

[2] Van der Heijden, B. (2002), "Prerequisites to guarantee life-long employability," Personnel Review, vol. 31 No. 1, pp. 44-61.

[3] S. Karnouskos, "Mobile payment: A journey through existing procedures and standardization initiatives," in IEEE Communications Surveys \& Tutorials, vol. 6, no. 4, pp. 44-66, Fourth Quarter 2004.

[4] AU, Yoris A. and R. J. Kauffman, "The Economics of Mobile Payments: Understanding Stakeholder Issues for an Emerging Financial Technology," Electronic Commerce Research and Applications. vol. 7, no. 2, pp. 141-164, 2008.

[5] J. Ondrus and K. Lyytinen, "Mobile Payments Market: Towards Another Clash of the Titans?" 10th International Conference on Mobile Business, Como, pp. 166-172, 2011.

[6] C. Kim, et al, "An empirical examination of factors influencing the intention to use mobile payment," Computers in Human Behaviour, vo. 26, no. 3, pp. 310-322, 2010.

[7] S. Brown, et al, "Workplace performance, worker commitment and loyalty," Journal Econ. Manage. Strategy, vol. 20, pp. 925-955, 2011.

[8] D. Kiron, et al, "Innovating with analytics," MIT Sloan Management Review, vol. 54, no. 1, pp. 47-52, 2012.

[9] A. McAfee and E. Brynjolfsson, "Big Data: The Management Revolution," Harvard Business Review, vol. 90 no. 10 , pp. 60-6, 68, 128, Oct 2012.

[10] "What is a retailer?". Accessed on: Oct. 14, 2018. [Online]. Available: https://ecommerceplatforms.com/glossary/retailer

[11] F. Joifin, "9 Digital Payments in Malaysia That You Need to Know About," Accessed on: Oct. 14, 2018. [Online]. Available: https://www.comparehero.my/blog/digital-payments-malaysia 
[12] The Star Online, "Banks no longer the only face of banking," May 17, 2018. Accessed on: Oct. 14, 2018. [Online]. Available: https://www.pressreader.com/malaysia/the-star-malaysia-starbiz/20180317/281479276942285

[13] V. Venkatesh, et al, "User Acceptance of Information Technology: Toward a Unified View," MIS Quarterly, vol. 27, no. 3, 2003.

[14] V. Ventakesh, et al, "Consumer acceptance and use of information technology: extending the unified theory of acceptance and use of technology," MIS Quarterly, vol. 36, no. 1, pp. 157-178, 2012.

[15] S. Taylor and P. Todd, "Understanding Information Technology Usage: A Test of Competing Models," Information Systems Research, vol. 6, no. 2, pp. 144-176, 1995.

[16] M. Limayem, et al, "How habit limits the predictive power of intention: the case of information systems continuance," MIS Quarterly, vol. 31, no. 4, pp. 705-737, 2007.

[17] C. D. Lanier and A. Saini, "Understanding Consumer Privacy: A Review \& Future Directions," Academy of Marketing Science Review, vol. 12, no. 2, pp. 1-31, 2008.

[18] D-H. Shin, "A socio-technical framework for cyber-infrastructure design: implication for Korean cyber-infrastructure vision," Technological Forecasting \& Social Change, vol. 77, pp. 783-795, 2010.

[19] F. Davis, "Perceived Usefulness, Perceived Ease of Use, and User Acceptance of Information Technology," MIS Quarterly, vol. 13, no. 3, pp. 319-340, 1989.

[20] M. Fishbein and I. Ajzen, "Belief, Attitude, Intention, and Behavior: An Introduction to Theory and Research," Reading, MA: Addison-Wesley, 1975.

[21] T. Olushola and J. O. Abiola, "The Efficacy of Technology Acceptance Model: A Review of Applicable Theoretical Models in Information Technology Researches," Journal of Research in Business and Management, vol. 4, no. 11, p. $70-83,2017$.

[22] A. Dillon and M. G. Morris, "User Acceptance of Information Technology: Theories and Models," Annual Review of Information Science and Technology (ARIST), vol. 31, pp. 3-32, 1996.

[23] C. Morosan and A. DeFranco, "It's about time: Revisiting UTAUT2 to examine consumers' intentions to use NFC mobile payments in hotels,"International Journal of Hospitality Management, vol. 53, pp. 17-29, 2016.

[24] G. Chelsea, "Using and Interpreting Cronbach's Alpha," University of Virginia Library Research Data, Nov. 16, 2015. Accessed on June 22, 2019. [Online]. Available: https://data.library.virginia.edu/using-and-interpretingcronbachs-alpha/

[25] J. A. Gliem and R. R. Gliem, "Calculating, Interpreting, and Reporting Cronbach's Alpha Reliability Coefficient for Likert-Type Scales,” Indiana Univesity - Purdue University Indianapolis (IUPUI), 2003. Accessed on June 22, 2019. [Online]. Available: https://scholarworks.iupui.edu/bitstream/handle/1805/344/Gliem\%20\&\%20Gliem.pdf?s

\section{BIOGRAPHIES OF AUTHORS}
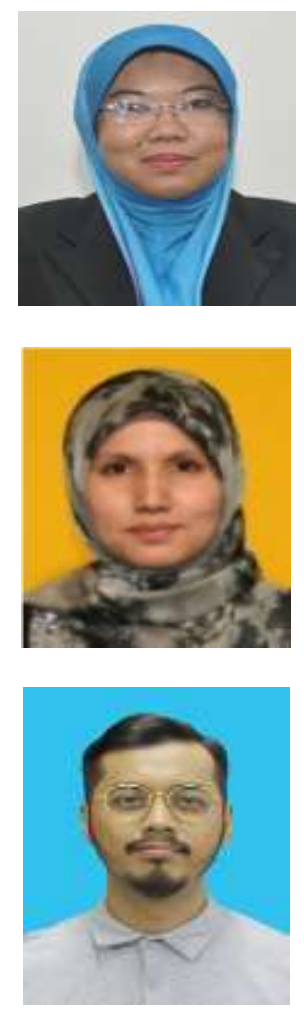

Ts. Dr. NorHapiza Mohd Ariffin received her BSc Hons in Computer Science (1994), MSc in Information Technology (IT) (2001) and Phd in Computer Science from Universiti Kebangsaan (UKM), Malaysia. Her research interests include Blockchain, Strategic Customer Relationship Management (CRM), Strategic Information System Planning (SISP), Performance Evaluation Support System, Human Capital, Spiritual Information System and, Online Distant Learning.

Fauziah Ahmad received her first degree in Business Administration majoring in finance at the University of Colorado, USA in 1998, MS Information technology at the Universiti Teknologi MARA in 2004, and currently pursuing her Ph.D. study in the area of IT project management. She currently holds a post as a senior lecturer at the Faculty of Computer and Mathematical Sciences, Universiti Teknologi MARA, Malaysia

Umar Bin Mohd Haneef received his Diploma in Computer Science (2016) and Bachelor of Information Technology (Hons.) Business Computing (2020) from Universiti Teknologi MARA (UiTM). His research interest was on financial technology (Fintech) which was mobile payment 